\title{
Edificio judicial de Tortosa
}

Josep Camps y Olga Felip

Aportación seleccionada por proceso de revisores en el Congreso FUARIENS

DOI: 10.5821/palimpsesto.19.8533

a tercera edición del Foro Universidad e Industria celebrado en la EISAB en abril de 2019 propuso un espacio de encuentro entre la actividad

universitaria docente e investigadora, y los tejidos

industrial y profesional del mundo de la arquitectura. Entre sus distintas actividades recogemos aquí una de as aportaciones del foro a cargo de los arquitectos Olga Felip y Josep Camps en binomio con Cémex, inscrita y presentada en la sección call for matters del congreso.

El edificio se sitúa en el caso antiguo de Tortosa,

rodeado de calles estrechas que condicionan la visión del mismo desde un punto de vista próximo y fugado. La textura de la fachada y el juego de los diferentes módulos permiten al peatón una visión diferente del edificio en cada punto de su perímetro.

La fachada se configura con una piel interior de hormigón in situ y una piel exterior de hormigón prefabricado tipo GRC (en colaboración con CEMEX).

Las piezas prefabricadas modulan la fachada y las aperturas y resuelven las diferentes situaciones que se dan en relación al interior y al exterior, al lugar y al programa.

Se ha buscado un color del hormigón que entona con el entorno del casco antiguo mediante aditivos de pigmentos en el hormigón.

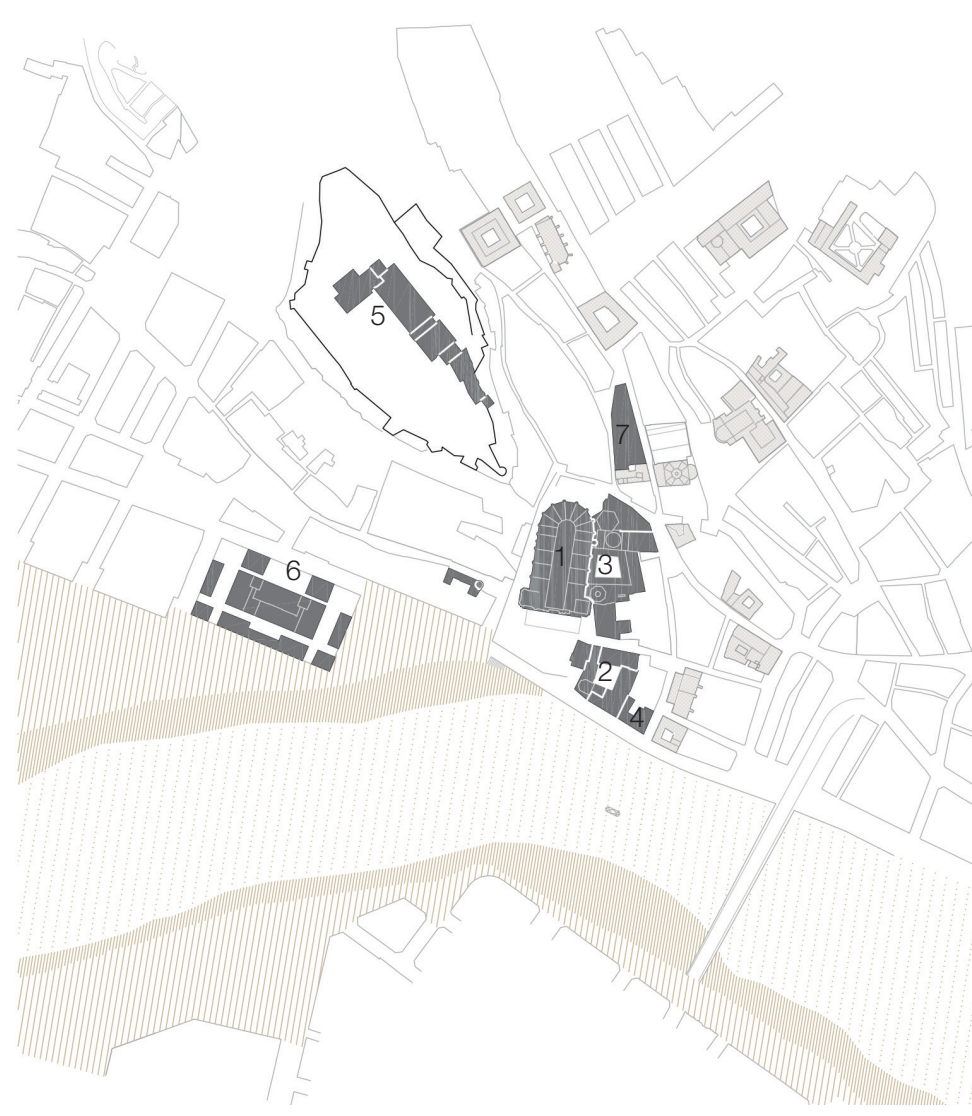

1. Catedral 2. Palacio episcopal 3. Museo catedralicio 4. Casa general 5. Castillo de la Suda 6. Museo de Tortosa (matadero) 7. Juzgados de Tortosa
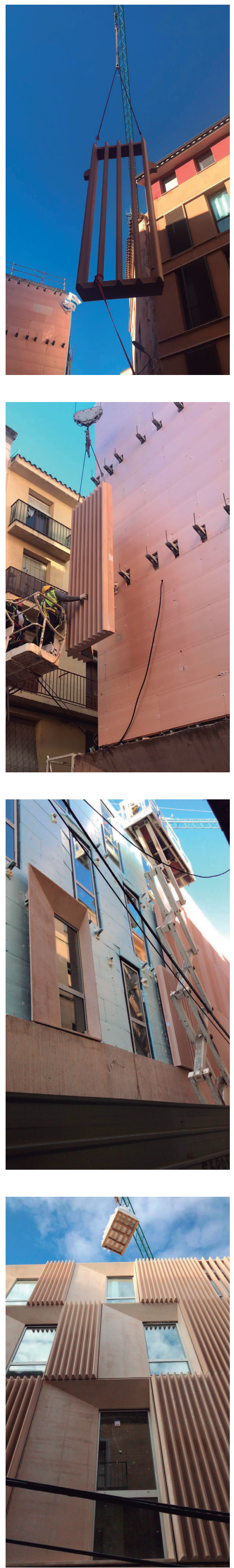

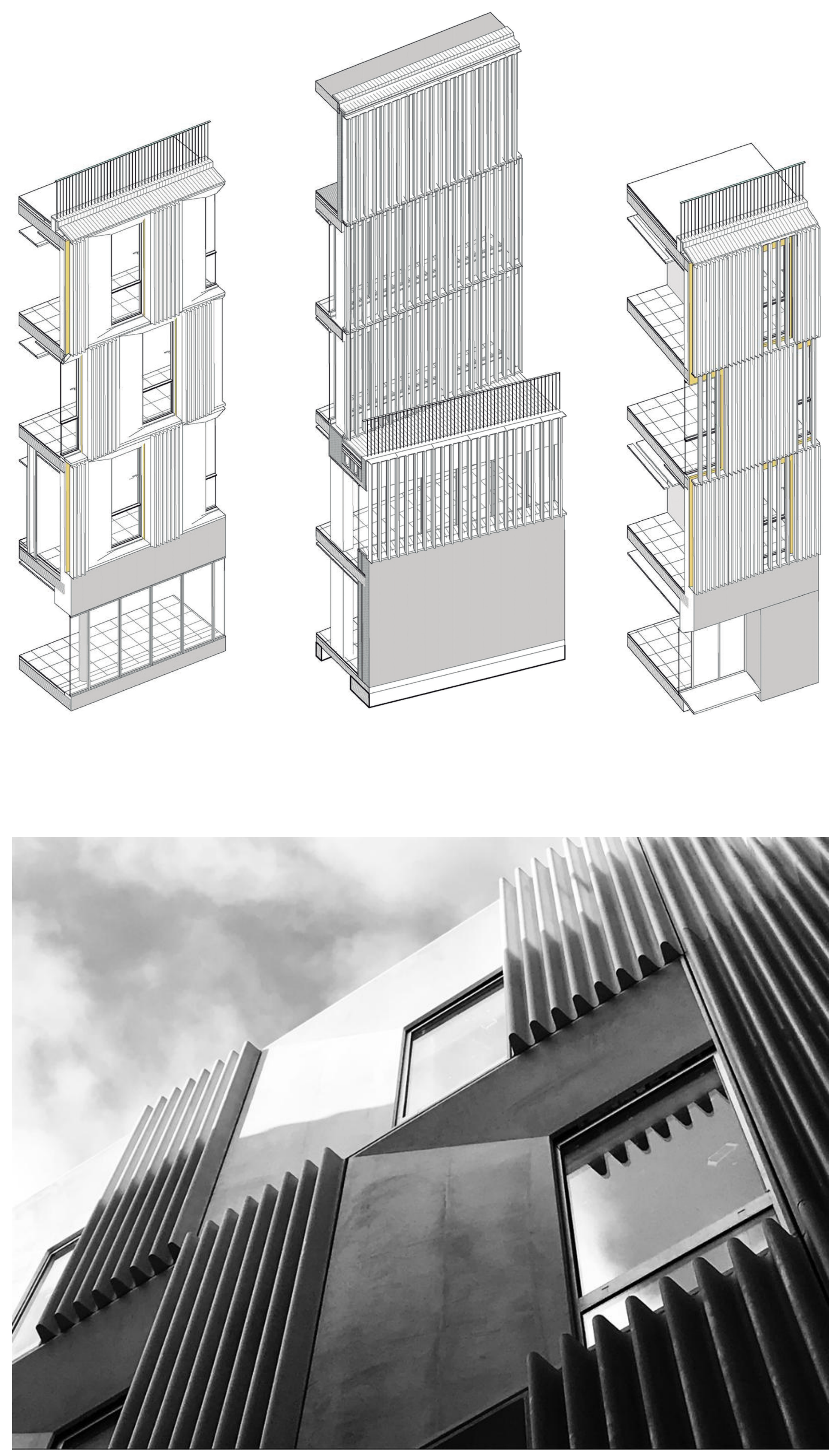